\title{
Bioequivalence Study of Generic Metformin Hydrochloride in Healthy Nigerian Volunteers
}

\author{
Adebanjo Jonathan Adegbola ${ }^{1}$, Olugbenga James Awobusuyi ${ }^{1}$, Babatunde Ayodeji Adeagbo ${ }^{1}$, \\ Bolanle Stephen Oladokun ${ }^{1}$, Adegbenga Rotimi Owolabi ${ }^{2}$ and Julius Olugbenga Soyinka ${ }^{{ }^{*}}$
}

${ }^{1}$ Department of Pharmaceutical Chemistry, Faculty of Pharmacy, Obafemi Awolowo University, Ile-Ife, Nigeria; ${ }^{2}$ Department of Medical Pharmacology and Therapeutics, Faculty of Basic Medical Sciences, Obafemi Awolowo University, Ile-Ife, Nigeria

\begin{abstract}
Background and objectives: Metformin is key in the management of type 2 diabetes mellitus but also represents additional financial burden, particularly with the use of branded products. The availability of generic products permits generic substitution with a much-reduced cost of treatment. However, only generic products that offer similar bioavailability with the innovator should be considered. This study was designed to assess the bioequivalence of generic metformin tablets within Nigeria.

Methods: Metformin tablets selected from the Nigerian market were appraised for quality following British and United States Pharmacopoeia guidelines. In vivo bioequivalence study in healthy volunteers was applied for a generic and the innovator brand in an open-label, 2-arm, 2-treatment crossover fashion with a 1-week washout period. Blood samples were collected at 0, 0.5, 1, 1.5, 2, 3, 4, 6, 8, 10 and $24 \mathrm{~h}$ post-dose. Plasma concentrations of metformin were analysed using a validated high-performance liquid chromatography method, and pharmacokinetic parameters were obtained using the non-compartmental approach. The formulations were considered bioequivalent based on the guidelines by United States Food and Drug Administration, Centre for Drug Evaluation and Research.

Results: Nine generic products met the quality assessment standards, and the in vivo bioequivalence study was carried out in 17 healthy volunteers. The mean values for $\mathrm{C}_{\max }, \mathrm{T}_{\max }, \mathrm{AUC}_{0-24}$, and $A \cup \mathrm{C}_{0-\infty}$ for the innovator brand of metformin were $0.43 \pm 0.14 \mu \mathrm{g} / \mathrm{mL}, 1.35 \pm 0.46 \mathrm{~h}, 2.03 \pm 0.68 \mu \mathrm{g} / \mathrm{mL}^{*} \mathrm{~h}$ and $2.63 \pm 1.11 \mu \mathrm{g} / \mathrm{mL}^{*} \mathrm{~h}$ respectively; for the generic product, the values were $0.44 \pm 0.13 \mu \mathrm{g} / \mathrm{mL}, 1.41 \pm 0.59 \mathrm{~h}, 2.04 \pm 0.68 \mu \mathrm{g} / \mathrm{mL}^{*} \mathrm{~h}$ and 2.85 $\pm 1.37 \mu \mathrm{g} / \mathrm{mL}^{*} \mathrm{~h}$. The $90 \%$ confidence intervals for the test formulation/reference formulation ratio for $\log \mathrm{C}_{\max }$ Log $A \cup C_{0-10 ~ h r}$ and $A U C_{0-\infty}$ were within the bioequivalence limits of $80 \%$ to $125 \%$ (95.8-106.8, 94.8-105.5 and 96.3-108.4 respectively).
\end{abstract}

Conclusions: The bioavailability of the test product was not inferior to innovator metformin.

Keywords: Metformin; Bioequivalence; Antidiabetic; Pharmacokinetics. Abbreviations: API, active pharmaceutical ingredient; AUC, area under plasma concentration-time curve; BCS, Biopharmaceutical Classification System; BE, bioequivalence; BMI, body mass index; BP, British Pharmacopoiea; CDER, Centre for Drug Evaluation Regulatory; Cmax, maximum concentration; EDTA, ethylene diamine tetraacetic acid; ER, extended release; GMR, geometric mean ratio; HPLC, high performance liquid chromatography; IR, immediate release; LOD, limit of detection; LOQ, limit of quantitation; OAD, oral antidiabetic drug; SNPs, single nucleotide polymorphisms; TDM, therapeutic drug monitoring; Tmax, time to reach maximum concentration; UKPDS, United Kingdom prospective diabetes study; USP, United State Pharmacopoiea

Received: March 16, 2017; Revised: July 15, 2017; Accepted: July 31, 2017

${ }^{*}$ Correspondence to: Julius O. Soyinka, Department of Pharmaceutical Chemistry, Faculty of Pharmacy, Obafemi Awolowo University, Ile-Ife, Nigeria. Tel: +2348035822785, E-mail: juliussoyinka@gmail.com

How to cite this article: Adegbola AJ, Awobusuyi OJ, Adeagbo BA, Oladokun BS, Owolabi AR, Soyinka JO. Bioequivalence Study of Generic Metformin Hydrochloride in Healthy Nigerian Volunteers. J Explor Res Pharmacol 2017;2(3):78-84. doi: 10.14218/JERP.2017.00010
Introduction

Metformin is an oral antidiabetic drug (OAD) belonging to the biguanide class. Other biguanides are phenformin and buformin, but the former was withdrawn from market due to reported links with serious cases of lactic acidosis. ${ }^{1,2}$ Metformin, however, remains the drug of choice in the management of type 2 diabetes mellitus, particularly in patients whose renal functions have not been compromised. According to the United Kingdom Prospective Diabetes Study (UKPDS), metformin is superior to other OADs in lowering both the macrovascular- and microvascular-related complications that characterize the disease progression in diabetic patients. ${ }^{3,4}$ Recently, some researchers have spoken out against the claims by UKPDS, citing methodological shortcomings. ${ }^{5}$ Despite 
<smiles>CN(C)C(=N)NC(=N)N</smiles>

Molecular weight, $129.1 \mathrm{~g} / \mathrm{mol}$

Fig. 1. Chemical structure of metformin.

this dichotomy, metformin remains a first-line drug in obese and non-obese diabetic patients, alongside lifestyle adjustment. ${ }^{6}$ It is considered superior to sulphonylurea because it causes no weight gain and it is rarely associated with hypoglycaemia. ${ }^{7,8}$ Moreover, it is safer than the thiazolinedidiones because it offers a cardioprotective effect instead of cardiotoxicity.,10

Metformin, 1,1-dimethylbiguanide (Fig. 1), has a low molecular weight $(129.1 \mathrm{~g} / \mathrm{mol})$, good solubility (about $300 \mathrm{mg} / \mathrm{mL}$ ) in polar solvents, resulting in solution with $\mathrm{pH}$ range of 1.2-6.8 at 25 ${ }^{\circ} \mathrm{C}$; however, its lipophilicity and permeability are unacceptably low. ${ }^{11}$ Metformin is provided as 500, 850 and 1,000 mg tablets, either as immediate release (IR) and extended release (ER) formulations. Glucophage ${ }^{\circledR}$ (a descriptive name to describe its role as a 'glucose-eater') is an innovator product that stands out in terms of quality and efficacy over time, but is relatively unaffordable for some patients. In general, the high-price associated with some branded products may predispose patients to opt for generic products, often registered by the drug regulatory body. In Nigeria, many generic products are in circulation, and they are often preferred by the populace because of the prevailing poor socioeconomic status. This trend has helped to curtail rising in pharmaceutical expenditure, especially in low- to middle-income countries. ${ }^{12}$ However, generic substitution should not be based solely on the initial cost of treatment but on the overall cost effectiveness of pharmacological treatment. ${ }^{12}$ As a result, a standard has been set for generic substitution. Interchangeability is permitted when the generic product demonstrates bioequivalence $(\mathrm{BE})$ and therapeutic equivalence with the innovator.

$\mathrm{BE}$ of a generic product could be determined by either in vivo or in vitro studies. In vivo $\mathrm{BE}$ studies are frequently used to establish therapeutic equivalence, but this approach is usually expensive and more rigorous and may require clinical trial or study expertise. ${ }^{13}$ In vitro dissolution profiles are proxies for establishing $\mathrm{BE}$ when the drug meets the criteria prescribed for a Biopharmaceutics Classification System (BCS) biowaiver. ${ }^{14}$ The BCS considers three major factors-dissolution, solubility and intestinal permeability-which influence the rate and extent of drug absorption from IR solid oral dosage forms. ${ }^{15}$ Metformin is highly soluble in water with poor permeability, and as such it is classified as a BCS class 3. It may enjoy a biowaiver if dissolution of $85 \%$ or more of the labelled amount of the active pharmaceutical ingredient (API) in both the generic and the innovator products is attainable within $15 \mathrm{~min}$ in standard dissolution media at $\mathrm{pH} 1.2,4.5$ and 6.8. ${ }^{14}$

An in vitro dissolution study on four generic products of metformin showed that none of the four brands of metformin tested met this requirement because the innovator product and two others did not achieve $85 \%$ dissolution in 15 min. ${ }^{16}$ In a similar study conducted by Olusola et al. ${ }^{17}$ in 2012 on eight generic products of metformin, only three met the criteria for BCS biowaiver after a physiochemical equivalence testing. Thus, using an in vitro dis- solution profile as a surrogate for in vivo BE is still debatable as in vivo-in vitro correlation has not been established for metformin in most cases. ${ }^{16}$ Developing countries will benefit from generic products, unfortunately the resources for testing drug quality is limited. Thus, this study aimed to assess the bioavailability of generic formulations of metformin versus that of the innovator product.

\section{Materials and methods}

\section{Materials}

Metformin $\mathrm{HCl}$ was obtained from AK Scientific chemicals (United States), high-performance liquid chromatography (HPLC) grade acetonitrile and methanol were obtained from Scharlau ${ }^{\circledR}$ Chemicals (Spain). Cimetidine and potassium hydrogen phosphate were purchased from Sigma-Aldrich ${ }^{\circledR}$ Chemical Company (Germany). The innovator product of metformin (coded as A) and 13 other generic products of metformin tablets (coded as B, C, D, E, F, G, H, I, J, K, L, M and N) were purchased from retail pharmacies in Ile Ife, Ilesa and Ibadan South-West, Nigeria. All were IR tablets and the products' manufacturers and their batch numbers are as follows: Merck Sante, France(50009, manufactured in July 2012); Hovid BDH, Malaysia (03-536 BD, manufactured in March 2013); Jiangsu Ruinian Pharm, China (111208, manufactured in December 2011); Fredun Pharmacutical, India (FT 362, manufactured in July 2012); NGC Plc, Nigeria (F0802, manufactured in June 2013); Medopharm, India (2G31, manufactured in July 2012); Drugfield Pharm., Nigeria (580302, manufactured in March 2011); Vitaphos Lab Ltd, Nigeria (V054, manufactured in August 2012); Rajat Pharmchem, India (RA 2001, manufactured in June 2012); Juhel Nig. Ltd, Nigeria (0015, manufactured in October 2012); Henan Topfond Ltd, China (120810740, manufactured in August 2012); Vapicare Pharm. India (FVU1201, manufactured in April 2012); Vapicare Pharm., India (EF21002, manufactured in October 2012); and Watson Global Pharm., Nigeria (20120801, manufactured in 2012).

\section{Chemical assay and dissolution testing}

Assay and in vitro BE comparison of the innovator and generic products of metformin were carried out as prescribed by the British Pharmacopeia (BP) 2013. ${ }^{18}$ The potency of metformin in each product was established using ultraviolet (UV) spectrophotometric techniques by measuring the absorbance of the stated solution of metformin at $232 \mathrm{~nm}$, with $\mathrm{A}_{1} \mathrm{~cm}^{1 \%}$ taken as 798 . The dissolution system complied with the requirements in the Monographs of the United State Pharmacopoeia for the dissolution test for tablets. ${ }^{19}$ Potassium dihydrogen phosphate buffer $(0.68 \% \mathrm{w} / \mathrm{v})$ was adjusted with $1 \mathrm{M}$ sodium hydroxide to $\mathrm{pH}$ 6.8. Samples for UV analysis were withdrawn at predetermined intervals over a period of $1 \mathrm{~h}$ and the dissolution profile of concentration versus time was plotted.

\section{In vivo BE study design}

Ethical approval for the study was given by the Institute of Public Health, Obafemi Awolowo University, Ile-Ife, Nigeria. Written informed consent was obtained from each voluntary subject before commencement of drug administration and sample collection. Healthy volunteers $(n=22)$ between the ages of 18 and 28 yearsold, with body weight ranging from 45 to $75 \mathrm{~kg}$, were recruited 
for the study. Each subject underwent a physical examination and medical history-taking, both conducted by a physician. After an overnight fast, the subjects were given a single oral dose of $500 \mathrm{mg}$ metformin $\mathrm{HCl}$ tablet. Two products, consisting of a test product and a reference product, were administered to the subjects in a crossover fashion.

Study inclusion criteria included strict adherence to the following parameters: healthy adults; $18-45$ years of age; non-smokers; not pregnant; and body mass index (BMI) between $18-32 \mathrm{~kg} / \mathrm{m}^{2}$. Medically healthy was determined according to medical history and findings of physical examination. All study participants were required to provide voluntary written informed consent and show willingness and ability to fast overnight. Exclusion criteria included: history of renal impairment; pregnancy or lactation; recent significant blood donation; recent participation in similar studies (within 28 days); evidence of alcoholism or drug abuse, especially of drugs that could cause hypoglycaemic effect; and history of hypersensitivity to biguanides.

\section{Study treatment}

The voluntary subjects were invited to the study centre at about 7:30 am on the study day. The subjects were told to observe overnight fasting prior to that day. The study was implemented as a single dose, two-period and two-treatment with a test and a reference product in crossover design. The test product was chosen based on its equivalence with the reference product as determined by the quality assessment using assay and dissolution profiling of the two products. During the first period, half of the subjects received $500 \mathrm{mg}$ metformin as the reference product, which was given as a single oral dose, while the remaining half received orally $500 \mathrm{mg}$ metformin as the test product. Venous blood samples were collected at $0,0.5,1,1.5,2,3,4,6,8,10$ and $24 \mathrm{~h}$ following drug administration. A 1-week washout period could ensure that the level of metformin in plasma had fallen far below the limit of quantitation. Then, subjects who received the test product in period 1 were treated with the reference product and vice-versa. Venous blood samples of the subjects were collected into ethylenediaminetetraacetic acid bottles at predetermined time intervals over $24 \mathrm{~h}$. The samples were centrifuged to obtain plasma and the plasma was stored at $-20^{\circ} \mathrm{C}$ until analysis in our Therapeutic Drug Monitoring (TDM) laboratory.

\section{Quantification of metformin in human plasma}

The analytical procedure involved modification of an extraction and HPLC method previously reported in the literature. ${ }^{20} \mathrm{~A} 1 \mathrm{mg} /$ $\mathrm{mL}$ stock solution of metformin and cimetidine were prepared by dissolving $25 \mathrm{mg}$ of each in a $25 \mathrm{~mL}$ volumetric flask using methanol, and the solutions were stored at $4{ }^{\circ} \mathrm{C}$. The chromatographic system consisted of an Agilent 1,100 series liquid chromatography system (Agilent Technologies, United States) fitted with a quaternary pump and a diode array UV detector (DAD; at 190-900 nm). Chromatographic separation was achieved at $25^{\circ} \mathrm{C}$ on a reversephase Agilent Zorbax (C18) column $(5 \mu \mathrm{m} \times 4.6 \mathrm{~mm})$ while the mobile phase was acetonitrile-potassium hydrogen phosphate buffer $(0.01 \mathrm{M}$, adjusted to $\mathrm{pH} 6.67), 55: 45$, applied at a flow rate of $1.2 \mathrm{~mL} / \mathrm{min}$. Sample was injected through a Rheodyne model 7725 valve (United States) fitted with a $20 \mu \mathrm{L}$ loop.

The eluents were monitored with UV detection at $234 \mathrm{~nm} \lambda \max$, while chromatograms were recorded with HP Chemstation software. To $100 \mu \mathrm{L}$ of plasma in a 2-mL Eppendorf tube was added
$50 \mu \mathrm{L}$ of $20 \mu \mathrm{g} / \mathrm{mL}$ cimetidine solution (internal standard), 100 $\mu \mathrm{L}$ of $8 \mathrm{M} \mathrm{NaOH}$ and $1.25 \mathrm{~mL}$ of 1-butanol/n-hexane (50:50, v/v), followed by shaking for $2 \mathrm{~min}$. After centrifugation at 10,800 $\mathrm{g}$ for $5 \mathrm{~min}$, the whole organic layer was separated and transferred into another tube. Metformin was back-extracted with $100 \mu \mathrm{L}$ of $1 \%$ acetic acid. The mixture was vortex-mixed and centrifuged for $1 \mathrm{~min}$. The organic phase was removed, and a $20 \mu \mathrm{L}$ volume of aqueous phase was injected into the chromatograph. The peak area ratio for each sample was generated from the peak response of metformin and cimetidine using UV detection at $234 \mathrm{~nm}$.

The assay was validated according to FDA draft guidance (CDER, 2013) to reflect acceptable linearity, sensitivity, specificity, accuracy and precision. Calibration curves were constructed within $0.05 \mu \mathrm{g} / \mathrm{mL}$ to $5.0 \mu \mathrm{g} / \mathrm{mL}$, based on the relationship between the peak area ratios and the standard solutions of metformin. A $100 \mu \mathrm{L}$ aliquot of drug-free plasma samples were spiked with $50 \mu \mathrm{L}$ of internal standard solution $(20 \mu \mathrm{g} / \mathrm{mL}$ cimetidine $)$ and standard solutions (between the range of $0.05-5.0 \mu \mathrm{g} / \mathrm{mL}$ ) of metformin.

For each sample, the above-stated extraction procedure was carried out and the supernatant $(20 \mu \mathrm{L})$ was injected into an HPLC column. A plot of peak area ratios versus concentrations of the standard solutions was made. The limit of detection (LOD) and limit of quantification (LOQ) were generated based on regression analysis of the calibration curve. Intra-day precision and accuracy were determined by analysis of five replicates of each QC level at $0.05 \mu \mathrm{g} / \mathrm{mL}, 0.5 \mu \mathrm{g} / \mathrm{mL}$ and $5.0 \mu \mathrm{g} / \mathrm{mL}$ concentrations. Inter-day precision was measured by analysis of duplicates of each QC concentration on three different days.

\section{Pharmacokinetic and statistical analysis}

The plot of plasma concentration $(\mathrm{C})$ against time ( $\mathrm{t}$ ) data of metformin was carried out using Microsoft Excel 2010. The data were analysed to obtain pharmacokinetic parameters using the non-compartmental model by means of the KINETICA Pharmacokinetic Software (United States). The results were recorded as mean \pm standard deviation (SD). $A U C_{0-10} h$ was computed using the linear method. The trapezoidal rule was applied when $C_{\mathrm{n}}>$ $C_{\mathrm{n}-1} . t_{0}$ was defined as $C_{0}$. The $A U C_{\mathrm{T}}$ was estimated as the sum of $A U C_{0-10} h$. The $A U C_{10} h \infty . k_{\mathrm{e}}$ was the elimination rate constant and was obtained as the slope of linear regression of the $\ln$ transformed plasma concentration-time curve in the elimination phase. Half-life $\left(t_{1 / 2}\right)$ was computed from $t_{1 / 2}=\ln (2) / k_{\mathrm{e}}$, clearance $(C L)$ from Dose/AUC $C_{\mathrm{T}}$ and volume of distribution $\left(V_{\mathrm{d}}\right)$ from $V_{\mathrm{d}}=$ $C L / k_{\mathrm{e}}=\left(t_{1 / 2} * C L\right) / 0.693$.

Comparisons of the pharmacokinetic parameters for the two products for determining BE were made using $t$-test and ANOVA by means of the SPSS 16 Software. After transforming BA parameters $\left(\mathrm{C}_{\text {max }}, A U C_{0-10} h, A U C_{\mathrm{T}}\right)$ to the logarithm scale, the data from both arms were compared by the $90 \%$ confidence intervals (CIs) using the ratio of geometric means. The test product was considered to be BE compared with the reference sample if the $90 \%$ CIs for $\mathrm{AUC}$ and $\mathrm{C}_{\max }$ were within the predetermined $\mathrm{BE}$ range of $80 \%$ to $125 \%$ (CDER, 2014).

\section{Results}

The innovator product and 13 generic brands of metformin were selected for preliminary quality appraisal screening by weight uniformity test, quantitative analysis and dissolution profiling. Twelve 
Table 1. Product description and quality assessment of metformin tablets distributed within Nigeria

\begin{tabular}{lllll}
\hline \multirow{2}{*}{ Product } & Weight Uniformity Test & UV-Assay (\% Content) & After 15 Min & After 45 Min \\
\hline A & Pass & & $70.6 \pm 0.20$ & $85.3 \pm 0.15$ \\
B & Pass & 96.1 & $86.7 \pm 0.27$ & $91.6 \pm 0.67$ \\
C & Pass & 100.0 & $82.9 \pm 0.21$ & $86.4 \pm 0.14$ \\
D & Pass & 96.1 & $44.6 \pm 3.12$ & $56.25 \pm 0.10$ \\
E & Pass & 93.9 & $78.8 \pm 0.20$ & $84.2 \pm 0.35$ \\
F & Pass & 98.6 & $76.5 \pm 0.19$ & $87.5 \pm 0.16$ \\
G & Pass & 100.2 & $81.0 \pm 0.36$ & $86.6 \pm 0.29$ \\
H & Pass & 92.9 & $58.0 \pm 1.46$ & $84.0 \pm 0.11$ \\
I & Pass & 98.5 & $55.5 \pm 0.78$ & $88.4 \pm 0.46$ \\
J & Fail & 99.8 & $67.5 \pm 0.50$ & $86.2+0.16$ \\
K & Pass & 95.2 & $2.5 \pm 0.17$ & $2.8 \pm 0.04$ \\
L & Pass & 100.2 & $87.7 \pm 0.22$ & $89.1 \pm 0.12$ \\
M & Pass & 95.6 & $84.6 \pm 0.23$ & $87.6 \pm 0.06$ \\
N & Pass & 95.3 & $89.0 \pm 0.06$ & $89.6 \pm 0.38$ \\
\hline
\end{tabular}

generic brands passed the weight uniformity test, while ten brands passed both the assay and dissolution tests, following the standard requirement stipulated by BP 2013 as they contained between $95-105 \%$ of the API of metformin and not less than $70 \%$ of API dissolved within 45 min during in vitro dissolution (USP, 2007).
Overall, nine generic products met all the standards stipulated in the official guidelines. The results for the assay and dissolution test are presented in Table 1 and Figure 2. Also, the quantity of metformin that went into solution within $15 \mathrm{~min}$ is presented in Table 1 , in order to show if the products rapidly dissolved to attain $85 \%$

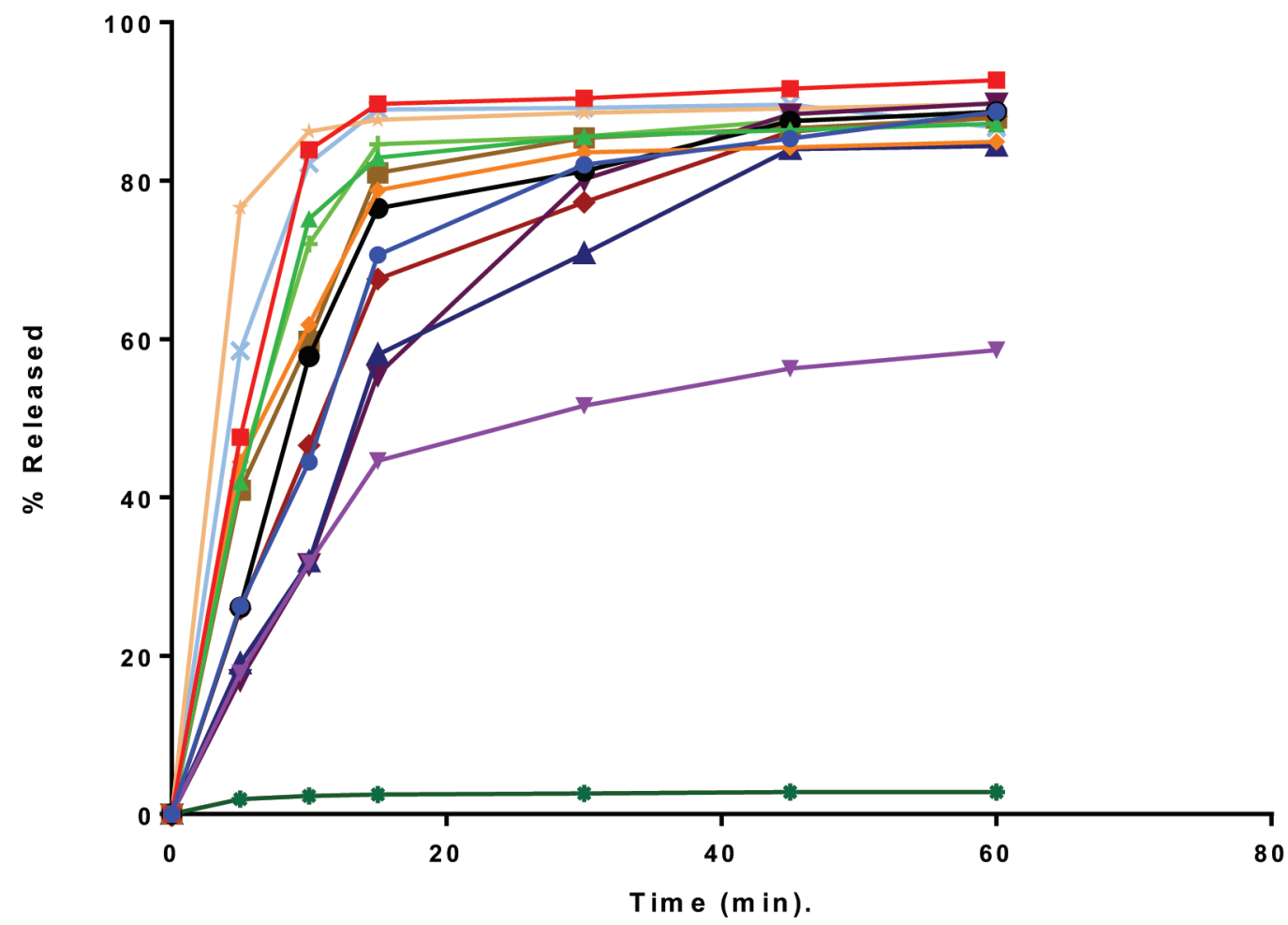

Fig. 2. Dissolution profile of metformin tablets in the Nigerian market. 
Table 2. Demographic features of the study participants

\begin{tabular}{ll}
\hline Demographic Features & \\
\hline Participants, total & 22 \\
Participants, completed the study & 17 \\
Gender, female/male & $6 / 11$ \\
\hline & \\
\hline Age (Years) & Mean \pm SD $^{\mathrm{a}}$ \\
Height (m) & $27.4 \pm 5.54$ \\
Weight (Kg) & $1.61 \pm 0.08$ \\
BMI (kg/m $\left.{ }^{2}\right)$ & $55.5 \pm 11.8$ \\
\hline
\end{tabular}

ameans \pm the standard deviation of Demographic features.

total release within 15 min with the aim of determining whether the products meet criteria for biowaiver. Though similar dissolution profiles were observed for all the products, except products $\mathrm{C}$ and $\mathrm{K}$, only three generic products rapidly released $\geq 85 \%$ metformin API. This led to the extension of this project to in vivo study.

For lack of resources, only product $\mathrm{B}$ was considered for in vivo comparative study. Seventeen healthy volunteers, including six females and eleven males, completed the in vivo study (Table 2). Treatment with both generic and innovator products was well tolerated. Metformin was quantifiable in all the subjects from $30 \mathrm{~min}$ to $10 \mathrm{~h}$ post-dose sampling points. The bioanalytical procedure for metformin analysis was validated based on FDA/CDER guidelines. The LOD and LOQ were 10.2 and $30.9 \mathrm{ng} / \mathrm{mL}$ respectively. Accuracy, recovery and intra-day and inter-day precision are presented in Table 3 . The average plasma concentrations-time profile of metformin for the innovator (reference) and the generic (test) products is depicted in Figure 3. Derived pharmacokinetic parameters, $90 \% \mathrm{CI}$ and geometric mean ratio (GMR) of the test/reference products for logarithm-transformed $\mathrm{BE}$ parameters $\left(C_{\max }, A U C_{0-10}\right.$ $h r$ and $\left.A U C_{0-\infty}\right)$ are presented in Tables 4 and 5.

\section{Discussion}

Out of 14 brands of metformin tablets in the Nigerian market, 10 products were found to be fit according to weight uniformity test, UV-spectrophotometric quantitative analysis and dissolution test. Eight of those products were generic and they were found to demonstrate pharmaceutical equivalence with the innovator brand by releasing $75 \%$ or more within 45 min using a basket rotating at $100 \mathrm{rpm}$. The products could have enjoyed in vivo biowaiver but some, including the innovator brand, were not sufficiently released in $\mathrm{pH} 6.8$ phosphate buffer during the dissolution test to meet the specification of $85 \%$ or more release within $15 \mathrm{~min}$.

Metformin is highly hydrophilic, with poor permeability and it belongs to class III of BCS. To establish in vitro BE-in vivo BE correlation, metformin products should release $\geq 85 \%$ of API within 15 min. ${ }^{15}$ The reason for this is that if the products rapidly dissolved under all physiological conditions, one will expect such products to behave like oral solutions in vivo. Only three generic products released $\geq 85 \%$ of its API within $15 \mathrm{~min}$. This pattern was similar to that of previously reported dissolution studies on metformin tablets in Nigeria, where the products were noted not to be rapidly dissolving in any of the three media having $\mathrm{pH} 2.0,4.5$ and 6.8. ${ }^{16,17}$ The feasibility of generic substitutions of OAD with the same amount and quality of API in the management of diabetes relies on the fact that the products are therapeutically equivalent and are able to offer glycaemic control of $<7.0 \% \mathrm{Hb} A 1 C$ and preprandial capillary plasma glucose of $80-130 \mathrm{mg} / \mathrm{dL} .{ }^{21}$

As in vitro BE-in vivo $\mathrm{BE}$ correlation is still debatable for metformin, further in vivo BE study was launched in accordance with the ICH guidelines on Good Clinical Practice and Guidance for Industry Bioavailability and Bioequivalence Studies. ${ }^{22,23}$ The test product was selected based on the prequalification dissolution test and assay of metformin tablets, while the innovator brand of $500 \mathrm{mg}$ metformin IR tablet served as the reference product. The healthy subjects treated with the test and reference products in a crossover fashion seemed to tolerate the treatment very well, as no adverse events were recorded. We started with 22 healthy volunteers, but we had to exclude 5 subjects because they contradicted the rule for this study either by taking other drugs during the study period, taking a meal unduly, or not being available at the time required for pharmacokinetic sampling.

In this BE study, metformin quantification from human plasma was achieved by adapting a simple, sensitive and selective HPLC method by Amini et al. ${ }^{20}$ This method was slightly modified and validated in our TDM laboratory. Samples were pre-treated by basification with sodium hydroxide, extraction with $50 \% \mathrm{v} / \mathrm{v}$ butanolhexane, and back-extracted with $1 \%$ acetic acid. Cimetidine was used in lieu of ranitidine. Though the LOD and LOQ in our study were slightly above the corresponding data generated by Amini's group, 10.2 and $30.9 \mathrm{ng} / \mathrm{mL}$ respectively compared with 5 and 15.6 $\mathrm{ng} / \mathrm{mL},{ }^{20}$ quantification of plasma levels of metformin at $0-10 \mathrm{~h}$ after a single oral dose of $500 \mathrm{mg}$ metformin tablet was adequately realizable.

All the findings for pharmacokinetic parameters in this study are in concordance with the other data reported previously. This study found $4.31 \pm 2.2 \mathrm{~h}$ as the half-life, $221.86 \pm 86.5 \mathrm{~L} / \mathrm{h}$ as the clearance, and $1,190.33 \pm 421.75 \mathrm{~L}$ as the volume of distribution respectively after a single oral dose of $500 \mathrm{mg}$ of reference product. The corresponding data for a single oral dose of test product are $5.67 \pm 1.74 \mathrm{~h}, 214.29 \pm 96.91 \mathrm{~L} / \mathrm{h}$ and $1,273.35 \pm 468.87 \mathrm{~L}$. The within-subject variability during the two treatments among the Nigerian healthy volunteers was low, as the average clearance and the average volume of distribution of metformin determined for both products were not statistically significantly different from each other.

However, wide variations in both clearance and volume of distribution do exist between subjects in this study. Similar findings

Table 3. Validation of bioanalytical HPLC- UV detection method for metformin

\begin{tabular}{lllll}
\hline \multirow{2}{*}{ Concentration, $\mu \mathrm{g} / \mathrm{mL}$} & Accuracy, \% $(n=6)$ & Recovery, \% $(n=6)$ & \multicolumn{2}{c}{ Precision, CV \% } \\
\cline { 4 - 5 } & & & Intra-day & 14.9 \\
0.05 & 78.0 & $98.0 \pm 1.82$ & 3.0 & 8.7 \\
5.0 & 103.2 & $83.9 \pm 0.83$ & 3.4 & 18.0 \\
\hline
\end{tabular}




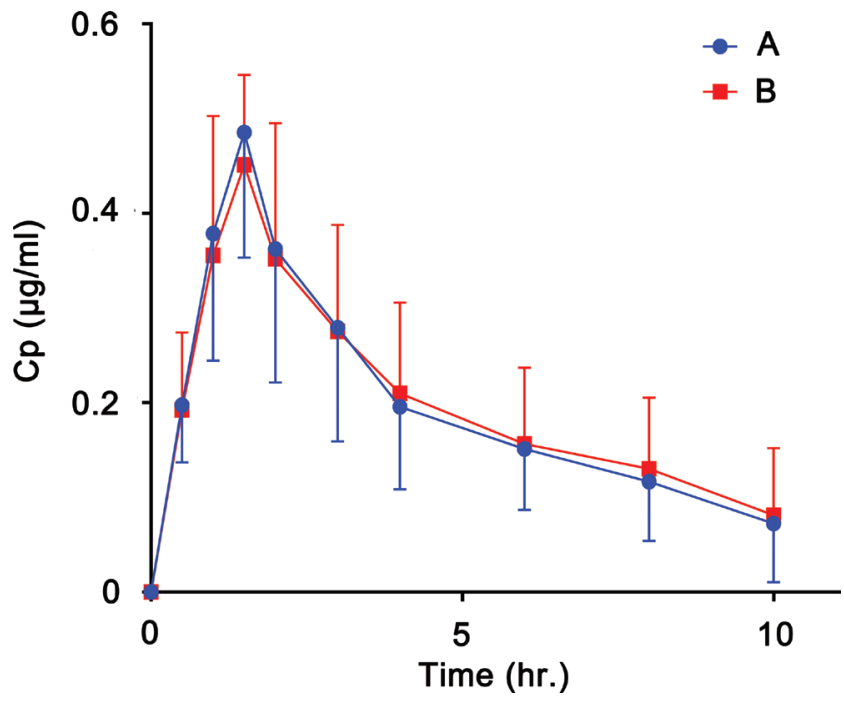

Fig. 3. Plasma concentration versus time profile of metformin following oral administration of an innovator and a generic product.

have been reported for metformin pharmacokinetics in another population. ${ }^{24}$ The reason put forward to explain these variations is inter-subject variability in the oral bioavailability $(\mathrm{F})$ of metformin and inter-subject variation in the ratio of the renal clearance of metformin to creatinine clearance which is independent of $\mathrm{F}$. Another strong rationale is the single nucleotide polymorphisms in metformin transporters-organic cation transporters in either healthy subjects and diabetic or obese individuals. ${ }^{24-27}$

Other pharmacokinetic parameters, such as maximum plasma concentration $\left(C_{\max }\right)$, time to reach the maximum concentration $\left(T_{\max }\right)$ and plasma exposure (AUC), were considered for the determination of BE of the two products. There was no significant difference for $C_{\max }, T_{\max }$ and $A U C$, as shown in Table 3. After logarithm transformation of BE parameters, the GMR and $90 \%$ CI was within the $\mathrm{BE}$ acceptable range, from $80 \%$ to $125 \%$.

Future research directions/recommendations

As a result of the great importance of generic drugs in healthcare, it is imperative that their pharmaceutical quality and in vivo performance be reliably assessed before they could be used interchange-
Table 5. Derived pharmacokinetic parameters of the test/reference products for logarithm-transformed BE parameters

\begin{tabular}{lll}
\hline Parameter & $90 \% \mathrm{Cl}$ & GMR Test/Reference \\
\hline $\log C_{\max }$ & $95.8-106.8$ & 101.3 \\
$\log A U C_{0-10 \mathrm{hr}}$ & $94.8-105.5$ & 100.2 \\
$\log A U C_{0-\infty}$ & $96.3-108.4$ & 102.3 \\
\hline
\end{tabular}

Abbreviations: $\mathrm{Cl}$, confidence interval; GMR, geometric mean ratio.

ably with the innovator product in the marketplace. It must be demonstrated that the safety and efficacy of the generic drugs are comparable to those of the innovator drugs.

\section{Conclusions}

This BE study found that the $500 \mathrm{mg}$ of the test product is equivalent to $500 \mathrm{mg}$ of the reference product of metformin. The outcome of the in vitro study correlates well with the in vivo study and both formulations met the regulatory standards for assuming BE in healthy volunteers.

\section{Acknowledgments}

The authors appreciate the facilitators and program coordinators of the bioequivalence online course organized by Karolinska Institute. The commitment of the subjects who participated in the in vivo study and the technical input of Babajide Shenkoya and Toyin in drug analysis are gratefully recognized.

\section{Conflict of interest}

The authors have no conflict of interests related to this publication.

\section{Author contributions}

Designing the research (JOS, AJA, BAA), recruiting volunteers (JOS, AJA, BAA, OJA, BSO, ARO), certifying medical fitness of volunteers (ARO), analysing samples (JOS, AJA, BAA, OJA, $\mathrm{BSO}$ ), preparing the manuscript (JOS, AJA, BAA, OJA, BSO,

Table 4. Derived pharmacokinetic parameters of metformin after oral administration of $500 \mathrm{mg}$ tablet of innovator and a generic product

\begin{tabular}{llll}
\hline Parameter & Reference A (Mean \pm SD) & Test B (Mean \pm SD) & $p$-value* \\
\hline$C_{\text {max }} \mu \mathrm{gg} / \mathrm{mL}$ & $0.43 \pm 0.14$ & $0.44 \pm 0.13$ & 0.8133 \\
$T_{\mathrm{max}^{\prime}} \mu \mathrm{g} / \mathrm{mL}$ & $1.35 \pm 0.46$ & $1.41 \pm 0.59$ & 0.5795 \\
$A \cup C_{\mathrm{L}^{\prime}} \mu \mathrm{g} / \mathrm{mL}{ }^{*} \mathrm{~h}$ & $2.03 \pm 0.68$ & $2.04 \pm 0.68$ & 0.9718 \\
$A \cup C_{\mathrm{T}^{\prime}} \mu \mathrm{g} / \mathrm{mL}^{*} \mathrm{~h}$ & $2.63 \pm 1.11$ & $2.85 \pm 1.37$ & 0.4434 \\
$t_{y^{\prime}, \mathrm{h}}$ & $4.31 \pm 2.2$ & $5.67 \pm 1.74$ & 0.0003 \\
$C L, \mathrm{~L} / \mathrm{h}$ & $221.86 \pm 86.5$ & $214.29 \pm 96.91$ & 0.6126 \\
$V_{\mathrm{d}^{\prime}} \mathrm{L}$ & $1,190.33 \pm 421.75$ & $1,273.35 \pm 468.87$ & 0.4426 \\
$V_{\mathrm{SS}} \mathrm{L}$ & $1,335.17 \pm 441.00$ & $1,371.33 \pm 382.01$ & 0.7110 \\
\hline
\end{tabular}

*Threshold of significance was set at $<0.05$. 
ARO)

\section{References}

[1] Lu HC, Parikh PP, Lorber DL. Phenformin-associated lactic acidosis due to imported phenformin. Diabetes Care 1996;19(12):14491450. doi:10.2337/diacare.19.12.1449.

[2] Rosand J, Friedberg J, Yang J. Fatal phenformin-associated lactic acidosis. Ann. Intern. Med 1997;127(2):170. doi:10.7326/0003-4819127-2-199707150-00034.

[3] Rojas LBA, Gomes MB. Metformin: an old but still the best treatment for type 2 diabetes. Diabetol Metab Syndr 2013;5(1):6. doi:10.1186/1758-5996-5-6.

[4] Boussageon R. Metformin in type 2 diabetes: where is the evidence? Ann Clin Exp Metabol 2016;1(1):1002.

[5] UK Prospective Diabetes Study (UKPDS) Group. Effect of intensive blood-glucose control with metformin on complications in overweight patients with type 2 diabetes (UKPDS 34). Lancet 1998;352(9131):854-865. doi:10.1016/S0140-6736(98)07037-8.

[6] Nyenwe EA, Jerkins TW, Umpierrez GE, Kitabchi AE. Management of type 2 diabetes: evolving strategies for the treatment of patients with type 2 diabetes. Metabolism 2011;60(1):1-23. doi:10.1016/j. metabol.2010.09.010.

[7] Hemmingsen B, Schroll JB, Wetterslev J, Gluud C, Vaag A, Sonne DP, et al. Sulfonylurea versus metformin monotherapy in patients with type 2 diabetes: a Cochrane systematic review and meta-analysis of randomized clinical trials and trial sequential analysis. CMAJ Open 2014;2(3):E162-E175. doi:10.9778/cmajo.20130073.

[8] Johnson JA, Majumdar SR, Simpson SH, Toth EL. Decreased mortality associated with the use of metformin compared with sulfonylurea monotherapy in type 2 diabetes. Diabetes Care 2002;25(12):22442248. doi:10.2337/diacare.25.12.2244.

[9] Azimova K, San Juan Z, Mukherjee D. Cardiovascular safety profile of currently available diabetic drugs. Ochsner J 2014;14(4):616-632.

[10] Schernthaner G, Currie CJ, Schernthaner GH. Do we still need pioglitazone for the treatment of type 2 diabetes?. Diabetes Care 2013;36(2):S155-S161. doi:10.2337/dcS13-2031.

[11] Desai D, Wong B, Huang $Y$, Tang D, Hemenway J, Paruchuri S, et al. Influence of dissolution media $\mathrm{pH}$ and USP basket speed on erosion and disintegration characteristics of immediate release metformin hydrochloride tablets. Pharm Dev Technol 2015;20(5):540-545. doi $: 10.3109 / 10837450.2014 .892132$.

[12] Nguyen TA, Knight R, Roughead EE, Brooks G, Mant A. Policy options for pharmaceutical pricing and purchasing: issues for low- and middle-income countries. Health Policy Plan 2015;30:267-280. doi:10.1093/heapol/czt105.

[13] Cook JA, Bockbrader HN. An industrial implementation of the biopharmaceutics classification system. Dissolution Technol 2002;9(2):68. doi:10.14227/DT090202P6.

[14] FDA/CDER. Waiver of in vivo bioavailability and bioequivalence studies for immediate-release solid oral dosage forms based on a biopharmaceutics classification system guidance for industry. U.S. Department of Health and Human Services, Food and Drug Administration, Center for Drug Evaluation and Research (CDER) 2015.

[15] Amidon GL, Lennernäs H, Shah VP, Crison JR. A theoretical basis for a biopharmaceutics drug classification: the correlation of in vitro drug product dissolution and in vivo bioavailability. Pharm Res 1995;12:413-420. doi:10.1023/A:1016212804288.

[16] Oyetunde OO, Tayo F, Akinleye MO, Aina BA. In vitro equivalence studies of generic metformin hydrochloride tablets and propranolol hydrochloride tablets under biowaiver conditions in Lagos State, Nigeria. J Diss Tech 2012:51-55. doi:10.14227/DT190412P51.

[17] Olusola AM, Adekoya Al, Olanrewaju OJ. Comparative evaluation of physicochemical properties of some commercially available brands of metformin hcl tablets in Lagos, Nigeria. J Applied Pharma Sci 2012;2(2):41-44.

[18] The British Pharmacopoeia 2013. Metformin monograph. The Stationary Office: London, UK 2013.

[19] United States Pharmacopoeia. Metformin monograph, USP 29-NF 24 Pharmacopeia Forum. 2007;31(4):1365.

[20] Amini H, Ahmadiani A, Gazerani P. Determination of metformin in human plasma by high-performance liquid chromatography. J Chromatogr B Analyt Technol Biomed Life Sci 2005;824(1-2):319-322. doi:10.1016/j.jchromb.2005.07.009.

[21] American Diabetes Association (ADA). Standards of medical care in diabetes. Diabetes Care 2016;39(Supp 1):S1-S106.

[22] ICHH Guideline. harmonized guideline for good clinical practice. E6 (R2) 2015.

[23] FDA/CDER. Guidance for industry bioavailability and bioequivalence studies submitted in NDAs or INDs - general considerations U.S. Department of Health and Human Services, Food and Drug Administration Center for Drug Evaluation and Research (CDER) 2014.

[24] Duong JK, Kumar SS, Furlong TJ, Kirkpatrick CM, Graham GG, Greenfield JR, et al. The pharmacokinetics of metformin and concentrations of haemoglobin $\mathrm{A} 1 \mathrm{C}$ and lactate in Indigenous and non-Indigenous Australians with type 2 diabetes mellitus. Br J Clin Pharmacol 2015;79(4):617-623. doi:10.1111/bcp.12525.

[25] Yoon H, Cho HY, Yoo HD, Kim SM, Lee YB. Influences of organic cation transporter polymorphisms on the population pharmacokinetics of metformin in healthy subjects. AAPS J 2013;15(2):571-580. doi:10.1208/s12248-013-9460-z.

[26] Christensen MM, Brasch-Andersen C, Green H, Nielsen F, Damkier $\mathrm{P}$, Beck-Nielsen $\mathrm{H}$, et al. The pharmacogenetics of metformin and its impact on plasma metformin steady-state levels and glycosylated hemoglobin A1c. Pharmacogenet Genomics 2015;21(12):837-850. doi:10.1097/FPC.0b013e32834c0010.

[27] Sam WJ, Roza O, Hon YY, Alfaro RM, Calis KA, Reynolds JC, et al. Effects of SLC22A1 polymorphisms on metformin-induced reductions in adiposity and metformin pharmacokinetics in obese children with insulin resistance. J Clin Pharmacol 2017;57(2):219-229. doi:10.1002/ jcph.796. 